some presenters had described it, was really only a relative strength. Highlighting the freedom of action or lack thereof may reveal the inner dynamics of a dictorial regime, he argued, but this emphasis must be placed in direct relation to the distinct tendency toward intellectual and social immobility. Historians should now turn to the techniques of oral history and the history of mentalités to uncover patterns of behavior, adjustment by defense, unwilling loyalty, resignation, improvisation, and Dacha-culture.

Despite substantive, methodical, and theoretical differences, virtually all conference participants agreed that the GDR should be understood as a society with its own structure and history of the social. This perspective gains in importance in comparison to standard political histories of the period, which tend to depict GDR society as primarily an orchestration on behalf of the party. These interpretations are not value-neutral: There is a hotly contested political dimension to the academic debate over the history of the GDR. Understanding the GDR as its own independent society with its own history rejects efforts to record it as a chapter of dictatorship in a national history of the Federal Republic and thus resists conservative efforts to recreate a German national history detached from the context of European integration. The techniques of social history may well give social-democratically oriented historians the weapons they need to reconquer terrain in the field of GDR research-now that, after the fall of the Berlin Wall, their colleagues in the social sciences who set the tone in the 1970s and 1980s with their convergence theories have been denounced as "academic helpers" for SPD-Ostpolitik or as secret SED collaborators.

\title{
Comparative International History of Dock Labour,
}

c. $1790-1970$

\author{
Colin J. Davis
}

University of Alabama at Birmingham

A conference on the "Comparative History of Dock Labour" was held in November 1997 at the International Institute of Social History, Amsterdam. Participating at the conference were labor historians whose subjects ran the gamut of dockers in Bombay, Mombasa, Tanga, Shanghai, Auckland, Freemantle, Antwerp, Bremen, Hamburg, Le Havre, Turku, Århus, Hull, London, Liverpool, Rotterdam, Haifa, and Glasgow. US labor historians, including myself, brought their area studies of New York, New Orleans, and San Francisco to the conference. This look at dockworkers across 
time and in different systems of economic development divulged remarkable similarities - but also deep disjunctures of experience and behavior.

The organizers created a thematic approach based on earlier port reports by the participants. Frederick Cooper (University of Michigan) began the proceedings with a paper discussing the relationship of dockworkers and labor history. Examining dockers, Cooper argued, could "play a healthy role in addressing the problems of labor history generally." That is, identifying the connections that dockers had with each other throughout the world and their "geographical proximity to other urban workers" within port cities and their "social relations" with family members and neighbors could usher in an intricate picture of working-class life across time and space.

The conference then proceeded with the thematic panels. Linda Cooke Johnson's (Michigan State University) paper on "criminality on the docks" discussed how dockers were either victims or perpetrators of crime. Breaking down the differing forms into "petty crime," "corruption," and "organized crime," Johnson highlighted how various forms of criminal behavior were attributed to structural conditions such as the casual labor system of dock work - but also to the predatory initiatives of gangsters. Colin Davis's (University of Alabama at Birmingham) paper on the "Formation and Reproduction of Dockers as an Occupational Group" examined how dockers obtained and dominated certain dock trades throughout the artisanal period and beyond. The question of familial relations caused lively debate, with some suggesting that greater empirical evidence needed to be obtained to balance the anecdotal.

The Friday morning session began with Klaus Weinhauer's (University of Hamburg) paper, "Casual Labour and Decasualization." It detailed the drift back and forth between these two labor systems. Highlighting the wretched labor conditions of the casual system of applying daily for work, Weinhauer was careful to balance this with the attraction such a system had for some dockers. As the discussion moved into the twentieth century, so did analysis of the role of state - whether colonial, authoritarian, or liberal. The session also examined the recent movement back to casualization in some European ports. Bruce Nelson's (Dartmouth College) paper, "Ethnicity, Race, and the Logic of Solidarity" detailed how these two conceptual constructions have played an enormous role in maintaining solidarity, but also exclusion. Though touching on ports throughout the world, Nelson's interpretation was centered around the U.S. experience and how the issue of "whiteness" has framed much of the labor segmentation within the industry. David De Vries's (Tel Aviv University) paper on the "Construction of the Image of Dock-Labor" incorporated a swath of dockers' self-images. Discussing ethnicity, drinking, masculinity, and "physical image," De Vries postulated common self-definitions in the world's ports. Such images were not framed by the harshness of the work alone but also 
by the apparent need of dockers to separate from surrounding workingclass neighborhoods and from women in general.

The afternoon session began with Mariam Dossal Panjwani's (University of Mumbai) explanation of how "space as [a] determinant" was created by dockers and their families. Echoing studies that highlight such spaces as "occupational communities," Panjwani discussed how men and women navigated the docker neighborhoods, whether on the streets or in saloons, clubs, and brothels. Such neighborhoods changed as the modern era encroached: As dockers moved away because of access to automobiles or destruction of housing, "space" became less an identifying construct of docker culture. Jessie Chisholm (St. Johns University, Newfoundland) followed with her paper on "Actions/Strategies." It focused on the organizational impulses of dockers to combat hostile employers and to call on national states for support and remedies for atrocious working conditions. Pushing the analysis further into the post-World War Two era, Chisholm explained how industrial conflict had changed. No longer were the issues over union recognition leading to the formation of rank-and-file docker movements-indifference to unions played a part as well.

In the Saturday morning session John Barzman (University of Le Havre) opened with his paper, "Dockers and the State." After outlining theoretical debates concerning state activity and purpose, Barzman described how national states involved themselves in dockers' lives because of the need for "total control of labor," to address "labor shortage," or to "boost productivity." As decasualization gained momentum, state action did, too, because of the twin fears of union power and political destabilization. The following session dealt with employers. Sam Davies's (Liverpool John Moores University) paper, "The Role of Employers," brought in a much-neglected dynamic of dockworker history. Splitting his discussion into two sections, "employment relations" and "industrial relations," Davies discussed how employers affected manpower levels, gang size, and sling loads. Just as important was what they could not control, and that was the labor process. True, foremen tended to align with employers-but the complex and at times skilled job of loading and unloading a huge array of cargoes ensured that dockers could retain a measure of control. The final paper, "The Work Process," was presented by Anna Green (University of Waikato). Green emphasized the changing nature of dock work while acknowledging that "skills and specialization" were constants. Although foremen held immense power in choosing who worked, "they were less successful at controlling men on the job." Green also discussed how such control was lost following cargo containerization. As the "traditional" gangs disappeared from the waterfront, they were replaced by isolated workers "operating sophisticated equipment."

Unfortunately, Latin-American dockers were absent from the discussion. Nevertheless, participants rightly regarded the conference a success. The conference allowed historians of dock labor to tap into the fertile 
comparative method to gain a greater insight into each others' work. By pinpointing the ubiquitous character of dockers and how they challenged the roles prescribed for them by employers, unions, and nation-states alike, the assembled labor historians discovered opportunities to place their work in larger contexts. Such comparative appreciation was critical considering the current Liverpool dockers' struggle. As Eric Taplin (University of Liverpool) pointed out, dockers throughout the world have shown commendable solidarity with Liverpool men and women. Such fellowship is likely to be shared by conference participants in building permanent links across the geographical spectrum.

\title{
Russian Labor History at the 1997 Convention of the
}

\author{
American Association for the Advancement \\ of Slavic Studies
}

\author{
Gerald Surh \\ North Carolina State University
}

Judging by the November 1997 meeting of the AAASS, the bulk of work in Russian labor history is still concentrated on the two or three decades preceding 1917-1918, notwithstanding the appearance of a single panel on "Labor Politics after Communism" and individual papers on Soviet period themes by Diane Koenker ("Sons against Fathers on the Shop Floor in Early Soviet Russia: Generation and Class in the Soviet Workplace") and Glennys Young ("Violence and Proletarian Identity, 1921-1932"). If this runs contrary to the overall shift of new research to the Soviet period, it may be due in part to the efforts of members of the newly formed Wildman Group for the Study of Workers and Society, which organized or participated in several panels at the conference.

A more apparent trend at the conference was a proliferation of labor and labor-related topics in diverse panels and under unexpected rubrics due to the reshaping of the parameters of labor history. Young's and Koenker's papers, for example, were presented in panels on "Newspapers as a Source" and "Youth in Conflict with Authority," respectively. Page Herrlinger read a paper on worker religious sectarians as part of a panel on urban religion. Tsuyoshi Hasegawa and Michael Hickey presented on crime and punishment in 1917 in St. Petersburg and Smolensk, respectively, and Hickey chaired another panel treating popular revolts (bunty) with papers on "The Bacchae of 1905: Attacks on Vodka Shops and Revolution- 